\title{
IR OU FICAR: O DILEMA DE UM JOVEM ADMINISTRADOR EM UMA EMPRESA DE ECONOMIA CRIATIVA QUE POSSUI UMA GESTÃO CONVENCIONAL
}

\author{
LEAVE OR STAY: THE DILEMMA OF A YOUNG MANAGER OF A BUSINESS OF CREATIVE ECONOMY \\ THAT HAS A CONVENTIONAL MANAGEMENT
}

\section{IR O QUEDAR: EL DILEMA DE UN JOVEN ADMINISTRADOR EN UNA EMPRESA DE ECONOMÍA CREATIVA QUE POSEE UNA GESTIÓN CONVENCIONAL}

\author{
HENRIQUE MUZZIO \\ Doutor \\ Universidade Federal de Pernambuco - Brasil \\ henrique.muzzio@ufpe.br \\ Submetido em: 06/01/2015 \\ Aprovado em: 20/11/2017
}

Doi: alcance.v24n4(Out/Dez).p591-601

\begin{abstract}
RESUMO
Objetiva-se analisar uma situação sobre o debate entre a permanência ou a saída de um jovem recém-formado que é efetivado em uma empresa de tecnologia da informação e comunicação (TIC). A organização possui uma trajetória vitoriosa, mas pode não ter um futuro tão promissor, dado seu modelo de gestão convencional e, aparentemente, não adequado ao contexto da criatividade. Trata-se de uma empresa localizada no Porto Digital, polo de economia criativa do Bairro do Recife. A empresa é uma desenvolvedora de aplicativos no efervescente mercado digital. A partir da perspectiva de um jovem administrador, o relato foi desenvolvido com base em duas entrevistas semiestruturadas. $O$ dilema é desenvolvido na perspectiva de permanência ou saída do profissional da empresa diante do modelo de gestão convencional aplicado em uma empresa da economia criativa.
\end{abstract}

Palavras-chave: Gestão criativa. Economia criativa. Modelo de gestão.

\section{ABSTRACT}

The objective of this teaching case is to analyze a dilemma of a young new graduate working for an information and communications technology (ICT) company, between staying with the company or leaving. The organization has a very successful history, but may not have as promising a future, due to its conventional model of management that apparently, is not suitable for the context of creativity. The company is located in Porto Digital, a cluster of the creative economy in Recife, Brazil. The company develops applications in the effervescent digital market. Based on the perspective of the young manager, the report was developed based on two semi-structured interviews. The dilemma is developed from a perspective of whether to stay or leave the company, faced with a conventional management model applied to a company of the creative economy.

Keywords: Creative management. Creative economy. Management model.

\section{RESUMEN}

Se objetiva analizar una situación sobre el debate entre la permanencia o la salida de un joven recientemente graduado que es contratado por una empresa de tecnología de la información y comunicación (TIC). La organización tiene una muy buena trayectoria, pero puede no tener un futuro tan promisorio, debido su modelo de gestión convencional y, aparentemente, no adecuado al contexto de la creatividad. Se trata de una empresa ubicada en Porto Digital, sucursal de economía creativa del Barrio de Recife. La empresa es una desarrolladora 
de aplicativos en el efervescente mercado digital. A partir de la perspectiva de un joven administrador, el relato fue desarrollado con base en dos entrevistas semiestructuradas. El dilema es desarrollado en la perspectiva de permanencia o salida del profesional de la empresa ante el modelo de gestión convencional aplicado en la empresa de economía creativa.

Palabras clave: Gestión creativa. Economía creativa. Modelo de gestión.

\section{INTRODUÇÃO}

O caso em análise enfatiza o modelo de gestão de uma empresa do segmento de tecnologia da informação e comunicação (TIC) que está baseado em uma gestão convencional, embora a empresa atue no segmento de economia criativa. O dilema, visto a partir da perspectiva de um coordenador, recém-formado, que foi efetivado na empresa após um período de estágio, foca se o profissional deve investir suas habilidades administrativas em uma visão transformacional de longo prazo no modelo gerencial vigente, ou se deve buscar outra empresa na qual ele possa desenvolver seus conhecimentos de uma gestão efetivamente criativa.

\section{DESCRIÇÃO DO CASO}

\section{O CONTEXTO}

A expectativa de muitos jovens que habitam o universo das empresas de tecnologia da informação e comunicação (TIC) é a realização do sonho de se tornar um destaque de sucesso mundial com a conquista de prestígio e riqueza, assim como alguns milionários ou bilionários que tanto a mídia mundial propaga. Para o jovem que aqui se analisa o enredo, a dúvida é ficar e apostar em um futuro longínquo de uma empresa em potencial ou sair, diante dos entraves de uma gestão pouco criativa.

O recém-formado em administração Samuel Santos acordou naquele dia de janeiro, uma segunda feira chuvosa que dificultava ainda mais o já caótico sistema de mobilidade urbana da cidade do Recife, de forma radiante. A razão era sua efetivação na empresa de Tecnologia da Informação em que antes atuava como estagiário. Localizada no Bairro do Recife, região do Porto Digital que concentra grande parte das empresas de economia criativa ligadas ao segmento digital da capital pernambucana, a empresa QWE Tecnologia fora formada há seis anos por três amigos do curso de Sistema de Informação em uma estrutura incipiente, sem muitos recursos, mas com muitas ideias de seus sócios. O tempo passou e agora a QWE é considerada uma empresa promissora em seu ramo de atuação, de desenvolvimento de aplicativos e consultoria tecnológica. Em constante crescimento, a empresa possui atualmente 39 funcionários efetivos, em sua maioria, jovens que veem no segmento de TIC uma oportunidade de uma carreira promissora $\mathrm{e}$, quem sabe, uma independência financeira igual àqueles ao redor do mundo que surfaram na onda das empresas de tecnologia.

Esse também é o sonho de Samuel. Com 23 anos e com o ideal de transformar o mundo, o jovem administrador, mas com um bom conhecimento de TIC, graças à sua curiosidade tecnológica, espera aplicar seus conhecimentos de gestão para impressionar os proprietários da QWE e, assim, galgar postos hierárquicos superiores. Diante do acelerado processo de crescimento que passa a empresa, especialmente com o seu recente primeiro contrato assinado com uma empresa estrangeira, Samuel foi contratado como coordenador administrativo, cargo que se reporta ao gerente Estevão Rodrigues, funcionário que está na empresa desde o seu primeiro ano de funcionamento e que possui uma ótima legitimidade perante os três sócios.

Mas, embora seja de um ramo da economia criativa, o modelo de gestão da empresa não está muito condizente com os princípios de uma gestão criativa, a começar pelo gerente Estevão, mas também pelos sócios, o que tem gerado em Samuel um dilema entre o protagonizado pela mídia e a realidade de sua empresa, ou, ainda, entre sua permanência apostando no longo prazo, ou sua saída em busca de uma organização que permita fluir suas ideias criativas. 


\section{O MODELO DE GESTÃO}

A QWE possui uma estrutura administrativa pequena. Com 39 funcionários, seu desenho organizacional é composto por três níveis hierárquicos (Veja figura no Anexo). O primeiro escalão é formado pelos três sócios, que dividiram a tarefa formalmente entre a Diretoria de Criação, a Diretoria de Mercado e a Diretoria Administrativa. A primeira cuida dos processos que envolvem o desenvolvimento de produtos e serviços disponibilizados. A segunda é responsável pelos contatos com o mercado de clientes, o que inclui prospecção e atendimento aos atuais. Por fim, a Diretoria Administrativa é responsável pela gestão de pessoal e o controle financeiro do negócio.

Apesar dessa divisão formal, na prática, os sócios acabam por "fazer de tudo um pouco". Isso é favorecido, em parte, pelo tamanho da empresa, que ainda permite tal condição, bem como pelo bom clima entre os sócios e pela compreensão geral do negócio que cada um possui. As reuniões de direção estão planejadas para ocorrerem uma vez por mês, mas tal prazo, por vezes, não é cumprido, seja por antecipações ou por postergações.

A gerência geral é ocupada por um profissional que possui alta confiança por parte da cúpula organizacional. Seu modelo de gestão é considerado um modelo clássico, no que tange ao modelo de liderança centralizador, ao sistema de controle baseado em metas e acompanhamento cotidiano e ao modelo burocrático de ação.

Quanto à gestão de pessoas, a QWE atua com o que se costuma chamar de básico. São poucas as ações que podem ser consideradas inovadoras, tal como os produtos que a empresa comercializa. As decisões são tomadas pela Diretoria e passadas pelo Gerente Geral sem maiores discussões com os funcionários. Não há um plano de carreira. Há uma equipe que cuida dos processos burocráticos legais, mas não há um departamento de gestão de pessoas. 0 treinamento não é uma política organizacional, dado que, na maioria das vezes, são os funcionários que veem a necessidade de atualização e estão, quase sempre, buscando aperfeiçoamento. A política salarial é pagar aquilo considerado como um "salário médio" do mercado.

\section{A EXPECTATIVA CRIATIVA}

Diante do sucesso alcançado por muitos jovens que aderiram ao mundo digital e da virtualidade, não são poucos aqueles que sonham com "milhões" de dólares em suas contas bancárias e com a fama cibernética. Samuel não é diferente e vê na QWE uma grande chance de realizar seu sonho.

Sua expectativa era máxima em ser um funcionário efetivo. Ele compartilhara seu entusiasmo com familiares e amigos. Esses, sem deixarem de ter um nível de inveja do colega. Samuel fazia mil planos que pretendiam inovar vários procedimentos que ele via como estagiário e que julgava nada criativo, mas não podia falar, pois ninguém ali dava ouvido a um simples estagiário, muito menos o gerente Estevão.

Samuel leu reportagens que ilustravam procedimentos, políticas e culturas de empresas visionárias que hoje são ícones. Microsoft, Google e Apple foram algumas delas nas quais o jovem coordenador buscou compreender alguns segredos para o sucesso, não só em relação aos produtos tão desejados pelos consumidores pós-modernos, mas também pela forma de gestão implantada nessas empresas.

Samuel era encantado pela motivação que muitos funcionários dessas empresas demonstravam, bem como pelos elogios que os mesmos faziam à maneira de ser de seus empregadores. Tudo isso só ampliava o entusiasmo de Samuel em ajudar a transformar a QWE em uma empresa inovadora não só em seus produtos, mas em seus processos e em sua cultura.

\section{A REALIDADE CONVENCIONAL}

Para ele, embora a empresa estivesse bem no âmbito competitivo, com franco crescimento e expansão de mercado, sob o ponto de vista administrativo, Samuel achava que a empresa estava longe do que ele vira em suas pesquisas em relação aos ícones da tecnologia.

Começava pelo ambiente. Sediada em um prédio antigo da histórica região recifense, as instalações da QWE em nada lembravam as fotos dos escritórios que se costuma ver em reportagens das melhores empresas para trabalhar. $\mathrm{O}$ ambiente era limitado fisicamente, em instalações antigas, com móveis convencionais e, ainda, o espaço era dotado de muitas barreiras em função da divisão de salas do antigo casarão. 
Porém, o que mais incomodava Samuel não era o físico, ainda que, para ele, possa ter grande valor simbólico e servir como uma vitrine para os clientes e para a sociedade em geral. O problema maior era subjetivo. Estava na maneira de ser da empresa, em seus valores e na postura de gestão de seus três sócios e do gerente.

Embora a empresa atuasse no mercado de economia criativa com o desenvolvimento de aplicativos (o que normalmente é associado a dinamismo e a comportamento inovador, para ficar em dois exemplos), na visão de Samuel, a cultura organizacional e o modelo de gestão pareciam dissociados com o mercado de atuação.

Sem contar, o clima organizacional. Samuel já conversara com alguns colegas de firma e percebera que a sua opinião já era um pouco evidenciada por outros nas conversas informais e mesmo nos momentos fora da empresa, como nos almoços e nos momentos de descontração em algumas noites.

Após um tempo de maturação, Samuel iniciou seu plano de tentar melhorar a realidade que, em sua visão, precisava se adequar ao mercado. Dialogou com alguns de seus pares e, então, pediu uma reunião para apresentar algumas ideias transformadoras para seu superior. Seus planos passavam por mudanças de layout da empresa, formas de contratação, sistemas de remuneração e relação entre os funcionários. Essas ideias não eram apenas expressões dialogadas, tudo estava escrito em forma de projeto (ainda que de maneira resumida).

A reunião fora marcada para uma segunda-feira, logo cedo, como era o costume de Estevão Rodrigues. Naquele horário, a empresa estava em relativa calma e se podia conversar de forma mais concentrada. Samuel então expôs suas ideias ao superior. Durante quase uma hora, o coordenador apresentou detalhadamente aquilo que ele entendia ser o melhor para a QWE.

Mas a segunda parte da reunião não foi bem como Samuel imaginara. Estevão reagiu de forma conservadora. Argumentou que as ideias não eram necessárias, ou, no máximo, não urgentes. 0 gerente disse que a empresa vai muito bem e os funcionários estão satisfeitos, inclusive "muitos queriam estar aquil". Estevão falou que a trajetória da empresa demonstrava uma estratégia adequada. Sua concordância parcial daquilo que fora dito por Samuel concentrou na questão física da empresa. Estevão disse que o espaço realmente já não suportava adequadamente o crescimento da empresa e que isso já tinha sido objeto de discussão em reunião da diretoria. Porém, o que mais incomodava Samuel, a cultura conservadora do modelo de gestão da empresa, em nada Estevão concordou ou, pelo menos, não expressou concordância.

O fim da reunião deixou Samuel um pouco desmotivado, mas aquilo não era o fim de sua tentativa. Dado o modo informal de relação dos sócios com os colaboradores e o tamanho da empresa (que facilitava o contato entre os níveis hierárquicos) ele tomou uma decisão: falaria com os sócios!

\section{MUDANÇA E RESISTÊNCIA}

Samuel colocou em prática a segunda parte de seu plano. Aproveitando-se do ambiente informal e da proximidade com os sócios, ele expôs a conversa que tinha tido com Estevão ao Diretor de criação. Esse, por sua vez, ouviu atentamente. Ao final, disse que a empresa estava bem, com um crescimento que Samuel já conhecia, que tinha conquistado novos clientes recentemente, enfim, que não via muita necessidade de mudança, mas que, de toda forma, tinha compreendido a mensagem de Samuel.

Nos próximos 45 dias o jovem coordenador não obtivera qualquer comentário sobre suas ponderações. Até achava que Estevão tinha modificado um pouco sua postura em relação a ele, o que the causou receios de uma retaliação.

Em um final de expediente que parecia ser como muitos outros, Samuel foi chamado para uma conversa com o Diretor de criação. Esse Ihe disse que suas questões tinham provocado dúvidas naquilo que o sócio pensava ser o futuro da empresa. Que tinha conversado com os outros sócios. Embora todos tivessem achado as questões pertinentes, os desdobramentos não foram uma unanimidade. Segundo o relato, o Diretor de mercado achava que precisaria de mudanças, mas essa ideia não encontrara eco na opinião do Diretor administrativo. Esse último achava que as práticas administrativas estavam adequadas, que os funcionários estavam satisfeitos, que 0 Gerente Estevão era uma pessoa comprometida, fiel aos princípios da empresa, que estava com eles desde o princípio.

O tempo passou e nenhuma mudança processual aconteceu. Samuel continuava com sua opinião, achava ainda que o "clima" estava pior, pois compartilhava com outros funcionários suas percepções e estes concordavam. Em geral, aquele entusiasmo inicial tinha se diluído entre os funcionários. A expectativa por adentrar 
em uma empresa do promissor mercado criativo não resistiu ao tempo e ao modelo gerencial, que, para eles, não estava adequada à imagem que seus colegas externos tinham da QWE, inclusive demonstrando interesse em participar da equipe. Se, para os "externos", Samuel ainda demonstrava o entusiasmo pela empresa, internamente, essa não 0 encantava, ainda que também não fosse 0 caso de ir à busca de outra oportunidade agora, pois 0 que ele colhia de depoimentos de conhecidos que atuavam em outras empresas da região era que a situação não seria muito diferente nas outras empresas de TIC da região.

\section{O FUTURO}

Samuel analisava a situação e se questionava entre suas duas possiveis trajetórias: apostar ainda na empresa que tinha um grande potencial ou sair em busca de outra organização na qual ele pudesse desenvolver suas ideias criativas. O jovem coordenador fazia indagações: A QWE caminhava para um momento decisivo em sua trajetória? Apesar dos bons números financeiros, as questões que emergiram a partir das provocações dele poderiam trazer consequências ao desempenho em um futuro próximo? Será que os sócios irão tomar decisões que levariam ao desconhecido ou irão permanecer no caminho que proporcionou chegar onde estão e com um futuro próximo bem-sucedido?

A cultura organizacional que caracteriza a QWE foi oriunda inicialmente daquilo que os fundadores entendiam como o mais adequado para a empresa. Mas outros valores foram colocados como alternativa com a chegada de novos integrantes, além disso, a dinâmica do setor de atuação da empresa é aguda. Samuel sabia que esse contexto dinâmico não dava garantias para que a empresa pudesse ser uma gigante no futuro.

Teria Samuel a razão? A mudança seria mesmo necessária ou isso seria uma visão de um jovem gestor que ainda não possuía a experiência necessária para compreender a realidade da QWE, inclusive por sua posição hierárquica intermediária, sem o conhecimento das estratégias a serem desenvolvidas pelos sócios? A cultura da empresa precisara mesmo mudar? Os valores estariam condizentes com o que se espera de uma empresa dita criativa? O crescimento recente garantiria uma posição privilegiada no futuro para a QWE?

O que Samuel deveria fazer: apostar na empresa, esperar uma chance para assumir uma posição hierárquica maior e, aí sim, tentar implantar suas ideias inovadoras com 0 incremento de práticas gerenciais criativas por meio de uma maior participação dos funcionários, um ambiente de maior liberdade criativa, de maior colaboração interdisciplinar para desenvolver uma cultura criativa na QWE? Ou devera simplesmente sair, indo em busca de uma empresa em que ele ocupasse uma posição hierárquica maior, mesmo com sua pouca idade e experiência de gestão, que permitisse realmente a implantação de suas ideias criativas? São dúvidas que permeiam o imaginário de Samuel. 


\section{NOTA DE ENSINO}

\section{OBJETIVOS EDUCACIONAIS}

Esse caso de ensino tem como objetivo principal subsidiar um debate a partir de uma análise comparativa de uma situação real, em torno da temática gestão criativa e cultura organizacional em um ambiente criativo. Diante da complexidade do contexto organizacional, temas correlatos também podem ser explorados em razão de outras variáveis que envolvem os processos de tomada de decisão, bem como que estão presentes no relato apresentado, dentre esses temas estão: mudança organizacional, liderança, gestão de carreira e motivação e estratégia empresarial.

Concentrando-se nas variáveis principais, o arcabouço teórico de mudança organizacional pode envolver, sem esgotar a análise, em algumas teorias: 1) Teoria contingencial - Diante da estreita relação entre as decisões organizacionais e o contexto socioeconômico que essas organizações estão envolvidas, ou seja, as variáveis ambientais, sem ser uma relação reducionista de causa-efeito, influenciam a maneira, o tempo e a intensidade de uma decisão, dado o contexto concorrencial. 2) Teoria neoinstitucional - As decisões empresariais estão fundamentalmente apoiadas em aspectos institucionais, em função de um comportamento mimético dos gestores, que tendem a se espelhar em decisões e comportamentos que são legitimados em razão de serem as decisões que os líderes de mercado executaram. Há ainda uma pressão institucional para moldar decisões em decorrência do poder coercitivo dos reguladores do mercado, tais como governos e órgãos de controle. Por fim, a decisão pode ser influenciada por uma pressão normativa, oriunda de um processo de profissionalização que legitima determinados padrões de comportamento, instrumentalizados, por exemplo, em instituições de formação ou em associações profissionais. 3) Teoria cultural - A cultura está apoiada em um amplo escopo de correntes teóricas, mas sua concepção simbólica possui uma grande legitimidade, nesse sentido, aspectos ligados a ritos, rituais, valores organizacionais, mitos, tabus, histórias, dentre outros, contribuem para a compreensão das razões de gestores e colaboradores tomarem (ou não) determinadas decisões. $O$ contexto de célere mudança que impacta nas organizações acaba por forçar gestores a adaptações que passam por uma convergência entre as estratégias e os valores culturais. 4) Teoria da liderança. Ao longo do tempo, o conhecimento sobre liderança tornou-se mais robusto para contemplar os crescentes desafios mercadológicos. Atualmente, a figura do líder é central nas estratégias e no processo de mudança organizacional. A partir de uma perspectiva de forte engajamento dos liderados, reconhece-se a importância de uma estratégia convergente entre os líderes, os liderados e o contexto.

Essas teorias podem ser exploradas em conjunto ou separadas para subsidiar o docente na condução da aplicação do caso de ensino, tanto em intervenções prévias, como instigando os participantes a analisarem o caso em função de tais concepções teóricas.

Sugere-se aplicação após explanações teóricas em aulas anteriores, da leitura pelos discentes de textos teóricos relacionados ao tema, bem como, posteriormente, ao uso de um filme que retrate cultura e mudança organizacional, para que os alunos possam fazer comparações, a partir da teoria, dos tópicos abordados entre a empresa investigada, a empresa apresentada no filme e a empresa na qual ele trabalhe. O professor pode sugerir a discussão que leve em consideração, dentre outros, se as decisões em debate seriam as mesmas, dada uma eventual diferença entre as empresas em relação à cultura organizacional, ao porte econômico, ao produto/serviço desenvolvido ou ao mercado de atuação.

Sugere-se ainda que a metodologia de ensino e transmissão do conhecimento seja: inicialmente, a leitura individual do caso. Após esse momento, os alunos podem realizar uma discussão intermediária em grupos menores (quatro a seis discentes, a depender do tamanho da turma). Por fim, todo o grupo, com a mediação do professor, faz uma discussão plenária, debatendo os pontos levantados e eventuais novos questionamentos surgidos no debate anterior entre os grupos menores.

Quanto à sua aplicabilidade, o caso pode ser usado com distintos graus de aprofundamento, em disciplinas de graduação e pós-graduação (especialização ou mestrado profissional), a saber: gestão de pessoas, administração de recursos humanos, processo decisório, cultura organizacional, gestão das mudanças e estratégia organizacional.

Espera-se que os alunos, ao explanarem suas interpretações e sugerirem o que fariam caso estivessem na empresa investigada, que façam conexões com a teoria previamente apresentada, bem como possam fazer um comparativo entre as realidades por eles vividas em suas respectivas organizações e o contexto relatado, 
ampliando assim a potencialidade desse caso de ensino quanto ao enriquecimento da capacidade de tomar decisão dos participantes, tudo isso liderado e mediado pelo professor.

Diante da possibilidade de o caso ser aplicado em disciplinas de graduação e de pós-graduação, esperase que as discussões tenham níveis distintos de aprofundamento, cabendo ao docente o reconhecimento do perfil da turma e das experiências dos discentes para conduzir a aplicação do caso em razão das diferentes realidades.

\section{FONTES DE DADOS}

Os dados para a elaboração do presente caso de ensino foram extraídos a partir dos relatos de dois entrevistados de uma pesquisa maior no âmbito da economia criativa financiada pelo CNPq. Foram realizadas entrevistas semiestruturadas, posteriormente transcritas. Os dados foram coletados na cidade de Recife, nas dependências da empresa investigada.

\section{QUESTÕES PARA DISCUSSÃO} discussão:

Sem esgotar as possibilidades de explorar o caso apresentado, sugerem-se quatro questões para

1) Quais elementos da cultura organizacional, tais como valores, crenças e rituais, você identifica na empresa apresentada e como você analisa a postura do funcionário Samuel em relação a essa cultura organizacional prevalecente?

2) Em relação à teoria sobre cultura e mudança, como você analisa a postura e o papel desempenhado pelo gerente Estevão no contexto apresentado? Para você, a empresa QWE está executando uma gestão da mudança organizacional de maneira satisfatória? Se não, por quê?

3) Em uma perspectiva de gestão de carreira e motivação, como o personagem deve proceder em relação à empresa QWE, usar uma estratégia de médio/logo prazo e desenvolver uma trajetória de aprendizado e desenvolvimento de carreira na empresa atual ou, diante da realidade apresentada, deve buscar uma recolocação tendo em vista seu potencial criativo e as circunstâncias do mercado de empresas de TIC?

4) É possível haver uma gestão criativa, assim como produtos criativos que são desenvolvidos pela QWE? Em sua opinião, o que poderia ser feito em relação à gestão da mudança para tornar o gerenciamento da empresa analisada mais criativo?

\section{REVISÃO DE LITERATURA E ANÁLISE}

Diante da conexão entre as questões apresentadas, a análise se dará em três blocos: Cultura Organizacional e Gestão da Mudança, Criatividade e Gestão, e Liderança, Carreira, Motivação e Estratégia.

\section{1 - Cultura Organizacional e Gestão da Mudança}

A literatura sobre cultura organizacional apresenta um campo altamente plural. É importante que os alunos tenham um conhecimento prévio dessa condição. Tal pluralidade é analisada por Smircich (1983) por diferentes conceituações de organização e de cultura, provenientes de diferentes concepções ontológicas da realidade social relacionadas à objetividade e à subjetividade, bem como pela concepção da natureza humana, nesse caso, determinística ou voluntarista. São duas as visões de cultura organizacional. Na primeira, a cultura é reconhecida como uma variável, aquilo que uma organização possui. Aqui há duas visões possíveis: i) "Gerência comparada" ou "cross-cultural", na qual a cultura é interpretada como uma variável independente; ii) "Cultura corporativa", em que a organização é interpretada como autoprodutora de cultura simbólica, em que estão presentes elementos como valores, rituais e tabus. Aqui, a organização é entendida como um sistema adaptativo ao realizar processos de troca com o ambiente, sem desconsiderar seu contexto interno. A cultura seria um subsistema organizacional, como o subsistema produtivo ou o subsistema administrativo.

Na segunda visão, a cultura é interpretada como uma metáfora, ou seja, aquilo que uma organização é, fruto das formas e das manifestações da consciência humana, não sendo apenas uma perspectiva econômica, mas também simbólica. Tal visão assume que o mundo social-organizacional só existe como um padrão de relacionamento e de significado simbólico, desenvolvido a partir de um processo humano interacional. Aqui se 
veem três perspectivas: i) A "cognição organizacional a cultura é um conjunto de conhecimentos e crenças compartilhadas que norteiam o modo de os indivíduos agirem; ii) $O$ "simbolismo organizacional", a cultura é vista como um sistema de símbolos e significados compartilhados que resultam das interações sociais dada a necessidade de interpretar a realidade e estabelecer critérios de ordenamento para as ações; iii) A "psicoestruturalista", a cultura é uma expressão do inconsciente humano (SMIRCICH, 1983).

Outra perspectiva, intraorganizacional, que já deve ser reconhecida previamente pelos discentes, é a feita por Martin (1992), que advoga a existência ou não de uma unicidade da cultura organizacional. A autora baseiase nas possibilidades de uma multiplicidade cultural, enfatizando três abordagens: integração, diferenciação e fragmentação, que estão associadas respectivamente a três tipos de interesse de pesquisa: gerencial, crítico e descritivo. A abordagem de integração está ligada ao referencial funcionalista e orienta-se pelo consenso no nível organizacional, em que a cultura é vista como homogênea, excluindo-se a possibilidade de ambiguidades. A perspectiva de diferenciação supõe um consenso em nível subcultural, assim, a organização tem espaço para diferentes subculturas, que podem conviver ou em harmonia, ou em independência ou em conflito. A abordagem da fragmentação analisa a organização como uma falta de consenso, uma multiplicidade de interpretações e foca na diversidade cultural e em sua consequente ambiguidade. Dessa forma, a integração é caracterizada pela harmonia, a diferenciação é marcada pelo conflito e a fragmentação tem como propriedade a multiplicidade. Em cada uma dessas perspectivas se encontram distinções para variáveis do contexto organizacional, tais como: 0 papel do líder, a influência do ambiente ou ainda o nível de análise das mudanças, que podem ocorrer no nível organizacional, suborganizacional ou individual.

A discussão, a partir das questões levantadas, pode explorar essas visões e perspectivas culturais e subsidiar a compreensão da cultura da QWE em que se busca compreender como os processos gerenciais e o comportamento dos envolvidos são embasados em suas condições culturais, a partir, por exemplo, de seus valores e do grau de integração ou não da cultura da QWE.

A cultura é composta por elementos que a estruturam e a definem. Os valores, as crenças, os mitos, os rituais e os ritos são exemplos de termos que foram associados ao contexto das organizações e muito contribuíram para a sua compreensão. Os valores refletem, explícita ou implicitamente, crenças, que são definidas como certas ou erradas, afetando todas as formas de comportamento organizacional. Esses valores, na ótica de Schein (2009), são também o elemento mais importante da cultura organizacional. Ele os relaciona a outros dois elementos, que formam uma tríade dispostos em níveis: os artefatos e criações, os pressupostos básicos e os valores. A distinção entre eles está baseada no quanto os mesmos são visíveis, decifráveis ou na maneira de acessá-los, ou seja, o quanto o fenômeno cultural é visível a um observador externo.

Hatch e Cunliffe (2006) afirmam que as crenças sustentam os valores à medida que aquilo que as pessoas assumem como verdadeiro influencia o que valorizam. De outro modo, os valores podem dar origem a crenças na medida em que, reafirmados consistentemente em comportamentos bem-sucedidos, passam a ser incorporados gradativamente como verdade, passando à categoria de pressupostos subjacentes.

No caso da QWE, o reconhecimento dos valores e das crenças que embasam a postura gerencial é importante para compreender a razão de agir de uma determinada maneira ou de outra. $O$ que leva ao aspecto do debate que se relaciona com mudança e resistência à mudança.

É sabido que a resistência à mudança é um comportamento esperado do ser humano. Diante da dinâmica do mercado que a QWE atua, as pressões institucionais e mercadológicas ampliam tanto a percepção de alguns por mudanças que acompanhem as transições conjunturais, como o sentimento de que a mudança não necessariamente é positiva, ou mesmo, não há uma percepção de tal necessidade.

Em convergência com a cultura organizacional, as organizações devem gerenciar as mudanças organizacionais (ABRAHAMSON, 2006) que ocorrem em função, por exemplo, de mudanças mercadológicas, introdução de novas tecnologias ou alterações no comportamento do consumidor. A estratégia empresarial está pautada na vantagem competitiva sustentável (PORTER, 1989). Para o alcance dessa vantagem, as organizações devem adequar suas estratégias à dinâmica de mercado, o que significa a existência de uma gestão da mudança, a qual precisa tentar se antecipar às tendências de mercado, aos comportamentos emergentes de seu públicoalvo e às eventuais modificações estruturais de mercado. Em mercados mais dinâmicos, como o de TIC abordado no caso, essa preocupação com a gestão de mudança deve ser ainda mais crítica, diante da característica de célere transformação que ocorre nesse ambiente, um fator desafiador para seus gestores. 


\section{2 - Criatividade e Gestão}

O fenômeno das indústrias criativas está relacionado a mudanças econômicas, tecnológicas e produtivas que transformaram o conhecimento em um ponto central da competitividade econômica. Na nova economia criativa, o capital tem forte base intelectual, fundamentando-se no indivíduo, em seus recursos intelectuais, na capacidade de formação de redes sociais e na troca de conhecimentos. A forma de produção das indústrias criativas tem como característica fundamental a criatividade, e a sua sobrevivência depende do sucesso em gerenciar os seus recursos criativos. Por sua vez, se os indivíduos criam e desenvolvem produtos criativos, é preciso desenvolver uma gestão capaz de alavancar esses recursos e garantir sua continuidade.

No caso da gestão não criativa, caso as ideias desse indivíduo criativo não venham a ser implementadas, sua criatividade deixa de ser aproveitada, dado o fato de que a geração de ideias e a efetivação da inovação constituem fases distintas (SOUSA; PELLISSIER; MONTEIRO, 2012). Nessa ordem, a efetividade criativa é um processo social de persuasão que também é influenciado pelas expectativas sobre o que o novo pode representar.

$O$ desafio da gestão criativa se pauta, nessa ordem, na avaliação de como as novas competências auxiliam os líderes no processo de transformação criativa. Isso requer o consentimento de práticas gerenciais oriundas de um indivíduo mais autônomo, representando tanto um mecanismo técnico, como um modo social e organizacional de compreensão do processo de absorção de tecnologias livres, abertura de espaços plausíveis para ideias diferentes e florescimento de formatos sistêmicos e contínuos de criação, transferência e retenção de conhecimento nas organizações.

No exemplo da QWE, a despeito da empresa ser atuante no setor da economia criativa, não a torna naturalmente, em uma empresa de gestão criativa, dado que isso ocorre não em função dos produtos comercializados, mas na maneira de liderar o processo gerencial.

\section{3 - Liderança, Carreira, Motivação e Estratégia}

Há uma vasta literatura sobre liderança em que é possível compreender como esse campo se desenvolveu ao longo tempo (BERGAMINI, 2009). Os estudos clássicos apresentaram desde a abordagem dos traços de liderança, que focou na qualidade do líder, a abordagem dos estilos de liderança, que tinha foco no comportamento da liderança, e a abordagem situacional, que concentrava nas contingências para garantir uma eficiência a esse processo. Atualmente, diante do processo acelerado de mudança e dos desafios colocados por um novo perfil funcional, a liderança incorporou elementos de criatividade para tornar esse processo mais condizente com esse contexto emergente. O Modelo de Liderança Criativa (MLC) (RICKARDS; MOGER, 2000) argumenta que líderes e liderados são capazes de alcançar níveis superiores de desempenho com o uso da criatividade, baseado em um estilo de liderança participativo.

No caso em questão, essa nova perspectiva da liderança pode ser analisada por meio de uma conexão com a gestão de carreira e motivação, na perspectiva do funcionário, bem como com a estratégia e a mudança organizacional na perspectiva empresarial.

Os nomes dos personagens e da empresa são ficcionais a pedido dos participantes.

\section{REFERÊNCIAS BIBLIOGRÁFICAS/INDICAÇÃO DE LEITURA}

ABRAHAMSON, E. Mudança organizacional: Uma abordagem criativa, moderna e inovadora. Harvard Business School Press, 2006.

ALCADIPANI, R.; CRUBELLATE, J. M. Cultura organizacional brasileira: Generalizações improváveis e conceituações imprecisas. Revista de Administração de Empresas, São Paulo, v. 43, n. 2, p. 64-77, 2003.

ALMEIDA, A. T. Processo de decisão nas organizações: Construindo modelos de decisão multicritério. São Paulo: Atlas, 2013.

BERGAMINI, C. W. (2009). Liderança. São Paulo: Atlas. 
BYRNE, C. L.; MUMFORD, M. D.; BARRETT J. D.; VESSEY, W. B. Examining the leaders of creative efforts: What do they do, and what do they think about? Creativity and Innovation, v. 18, n. 4, p. 256-268, 2009.

CARRIERI, A, de P.; SARAIVA, L. A. (Org). Simbolismo Organizacional no Brasil. São Paulo: Atlas, 2007.

DIMAGGIO, P. J.; POWELL, W. W. A Gaiola de ferro revisitada: Isomorfismo Institucional e Racionalidade Coletiva nos Campos Organizacionais. RAE-Revista de Administração de Empresas, v. 45, n. 2, p. 74-89, 2005.

FLORIDA, R. A. Ascensão da classe criativa: e seu papel na transformação do trabalho, do lazer, da comunidade e do cotidiano. Porto Alegre: LPM, 2011.

FREITAS, M. E. Cultura organizacional: formação, tipologias e impactos. São Paulo: Makron Books, McGrawHill, 1991.

HATCH, M. J.; CUNLIFFE, A. L. Organizations Theory: modern, symbolic, and post-modern perspectives. 2. ed. New York: Oxford University Press, 2006.

MARTENS, Y. Creative workplace: instrumental and symbolic support for creativity. Facilities, v. 29, n. 1, p. 6379, 2011.

MARTIN, J. Culture in organizations: three perspectives. New York: Oxford University Press, 1992.

MARTIN, J.; FROST, P. Jogos de guerra da cultura organizacional: A luta pelo domínio intelectual. In: CLEGG, S.; HARDY, C.; NORD, W (Org.). Handbook de estudos organizacionais, 2: reflexões e novas direções. São Paulo: Atlas, p.219-251, 2001.

MEYER, J. W.; ROWAN, B. Institutionalized organizations: Formal structure as myth and ceremony. American Journal of Sociology, v. 83, n. 2, p. 340-363, 1977.

PARJANEN, S. Experiencing creativity in the organization: From individual creativity to collective creativity. Interdisciplinary Journal of Information, Knowledge, and Management, v. 7, p. 109-128, 2012.

PETTIGREW, A. M. On studying organizational cultures. Administrative Science Quarterly, v. 24, p. 570-581, 1979.

PORTER, M. E. Vantagem competitiva - criando e sustentando um desempenho superior. Rio de Janeiro: Ed.

Campus, 1989.

RICKARDS, T.; MOGER, S. Creative leadership processes in project team development: an alternative to Tuckman's stage model. British Journal of Management, v. 11, n. 4, p. 273-283, 2000.

SCHEIN, E. H. Cultura organizacional e liderança. São Paulo: Atlas, 2009.

SMIRCICH, L. Concepts of culture and organizational analysis. Administrative Science Quarterly, v. 28, n. 3, p. 339-358, 1983.

SOUSA, F. C. DE; PELLISSIER, R.; MONTEIRO, I. P. Creativity, innovation and collaborative organizations. The International Journal of Organization Innovation, v. 5, n. 1, p. 26-64, 2012.

TRICE, H. M.; BEYER, J. M. Studying organizational cultures through rites and ceremonials. Academy of Management Review, v. 9, n. 4, p. 653-669, 1984. 
ANEXO

Figura 1: Organograma da Empresa

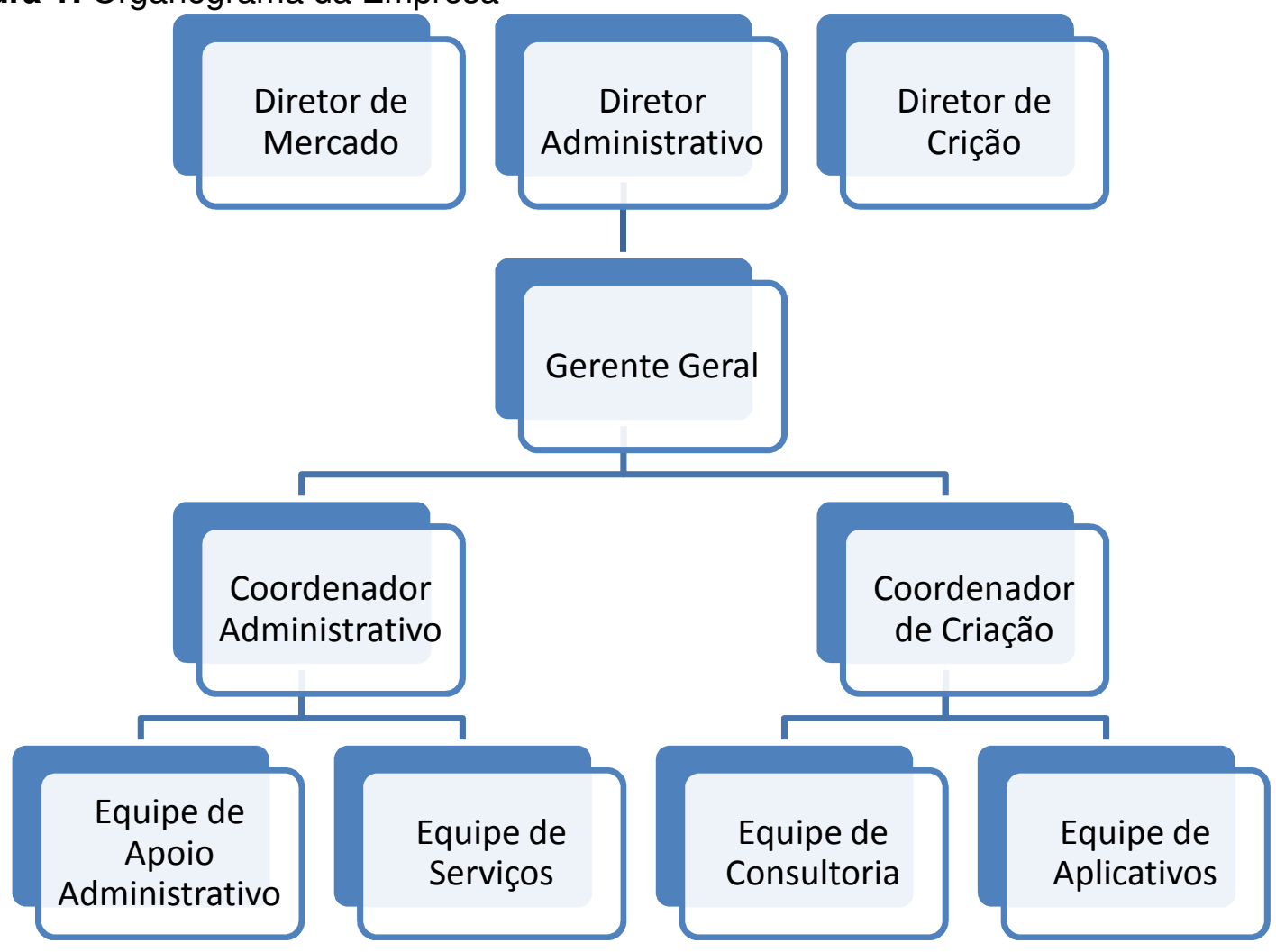

Fonte: Elaboração Própria. 